\title{
nature
}

\section{In pursuit of usefulness and distraction}

\section{Nature has been redesigned. It is to be hoped that this development, and others introduced in this issue, will enhance not only the publication's value but also its capacity to divert.}

nspect those little vertical lines in the 'footer' at the bottom left of this page, on either side of the volume number. They are a purely artistic element, empty of symbolism, pregnant with nothing but the vision of a designer. They are at the functionless end of the spectrum of changes made in a significant redesign of this publication. At the other, functional end is a set of typefaces that are subtly different from their predecessors in their combinations of size, shape and spacing, and all the more readable for that. In between are new uses of colour, changes in style of presentation and we hope, as a result, enhanced accessibility and clarity.

Nature owes its designers, Esterson Lackersteen of London, a debt of thanks not only for their inspiration but also for their tolerance in having their ideas pulled apart and reconstituted during the trials of editorial practicality and prejudice that all redesigns have to undergo. We are also indebted to groups of readers convened in the United States, Japan, the United Kingdom and Germany who provided useful criticisms and, above all, considerable encouragement to proceed with this development.

As well as the new design, this issue sees the inauguration of several enhancements in content. Authors and readers alike will be pleased to see that we are phasing in the incorporation of titles of papers in the reference lists of Letters, Articles, and Review and Progress Articles (see page 233). The only disadvantage to this development is that authors will find editors somewhat less flexible in enforcing our standard limits on the numbers of references. This is yet another step in our drive for ever more readerand author-friendliness of the original science that we publish, following hard on the heels of the introduction of Methods sections, increased flexibility in the presentation of figures and enhanced

\section{readability of introductory text.}

Time and again, surveys of readers highlight the popularity of our News and Views section. On page 207 is the first example of a new and occasional component: the News and Views Feature. The aim here, as is well illustrated by Christof Koch, is to provide a wide-angle snapshot of a set of recent advances that amount to an important stage in the development of a discipline. Articles of this type will provide a useful complement to the regular coverage in News and Views, being commissioned on the same principles of timeliness and authority. Above all, the editorial emphasis will be on interest and accessibility to a wide set of readers, as opposed to the more in-depth and specialized treatment appropriate to Review Articles.

The Book Reviews section also receives a boost. Following the recent introduction of the "at a glance" reviews of specialized tomes (see page 218), this issue sees the first discussion of a book "in retrospect" (page 217). Nature readers are, of course, cultivated people who read widely and reflect intelligently and unpredictably on what they have encountered. We know that many of them have the ability to transmit their reflections and thereby stimulate their fellow Nature readers. So, from time to time, we will publish such thoughts on books or other materials that may have been published at any time, and may have been inspiring, unusually provoking or even pernicious in their impact.

These developments, along with others over the past year, are part of a continuing process of evolution (although our mutations are, we would claim, less random than occurs in the wild). On that basis, this publication should continue to provide its readers with an ever more welcome distraction from, as well as support for, their everyday tasks.

\section{A rush tojudgement?}

\section{No amount of purely scientific argument seems likely to dispel public concern about Gulf War syndrome.}

$\square$ resident Bill Clinton's Advisory Committee on Gulf War Veterans' Illnesses has agreed to stay in place beyond its initial term of 18 months, keeping an eye on the collection of ailments known as GulfWar syndrome. The panel shows admirable devotion to duty, for it must know that nothing it says or does is likely to satisfy the substantial body of opinion that believes the veterans are suffering because of their experiences in the Gulf, and that government agencies and the medical profession have been covering up ever since.

The advisory committee concludes in its report, published last week (see page 187), that current scientific evidence "does not support a causal link" between the symptoms reported today by Gulf War veterans and exposure to any of the commonly discussed environmental risk factors. In fact, the report suggests that the reported ailments may be little more than the stress-induced symptoms familiar to veterans of every major conflict of this century. But the current political atmosphere in the United States, characterized by a strong distrust of the federal government, is not conducive to this explanation.

Three studies published this week in the Journal of the American Medical Association suggest, on the basis of self-reported information from a small group of veterans, that GulfWar syndrome consists of several neurological syndromes caused by exposure to a combination of chemical weapons, vaccines and insecticides. Despite the apparent limitations of the studies, they were subsequently used at a Senate hearing last week to exploit public sympathy for the veterans and lambast the president's panel for its conservative findings.

There is a danger that the issue could develop a public profile disproportionate to the nature of the problem, as has happened with the 'prisoners of war - missing in action' issue which has fixated many Vietnam War veterans for the past twenty-five years. Gulf War syndrome has yet to establish its medical credibility; it could still prove ultimately of greater interest to social historians than to medical researchers. 